\title{
PENGARUH KESADARAN EMOSIONAL, RASA PERCAYA DIRI, KONTROL EMOSIONAL TERHADAP KINERJA GURU SEKOLAH MENENGAH ATAS (SMA)
}

\author{
Muhammad Donal Mon \\ ${ }^{1)}$ Program Studi Manajemen, Universitas Internasional Batam \\ J1 Gajah Mada, Baloi Sei Ladi Batam 29442 \\ email: muhammaddonalmon@yahoo.co.id
}

\begin{abstract}
The performance of high school teachers (SMA) is very important in education, several factors that influence emotional intelligence from the teacher itself. On this occasion the independent variable was emotional self-awareness, self-confidence, emotional self control, while the dependent variable was teacher performance. Research data retrieve using a questionnaire, to measure how much influence emotional intelligence has on teacher performance. Data is processed using the SPPS program. The results of the analysis show that two variables of emotional intelligence have a positive and significant effect on teacher performance while self-confidence has a positive and not significant effect on teacher performance. Furthermore, the adjusted $R$ square is obtained at $65.0 \%$, influenced by these three factors, $35 \%$ is the contribution of other variables not included in this study.
\end{abstract}

Keywords: Emotion Inteligence, Teachers Performance, Senior High School

\begin{abstract}
Abstrak
Kinerja guru Sekolah Menengah Atas (SMA) merupakan hal yang sangat penting dalam pendidikan beberapa faktor yang mempengaruhi adalah emotional intelligence dari guru itu sendiri. Pada kesempatan ini yang menjadi variabel independen adalah emotional self awarness, self confidance, emotional self control, sedangkan variabel dependen adalah kinerja guru. Cara pengambilan data penelitian dengan menggunakan kuesioner, guna mengukur seberapa besar pengaruh kecerdasan emosional terhadap kinera guru. Data di olah menggunakan program SPPS. Hasil analisis menunjukkan bahwa dua variabel dari kercerdasan emosional berpengaruh positif dan signifikan terhadap kinerja guru sedangkan self confidance berpengaruh positif dan tidak signifikan pada kinerja guru. Selanjutnya adjusted $R$ square didapatkan sebesar 65,0 \% dipengaruhi oleh ketiga faktor tersebut, 35\% lainya merupakan konrtribusi dari variabel lainya yang tidak termasuk dalam penelitian ini.
\end{abstract}

Kata Kunci: Kecerdasan Emosional, Kinerja Guru, Sekolah Menengah Atas

\section{PENDAHULUAN}

Faktor penentu dari negara maju dan sedang berkembang dilihat dari tingkat dan kualitas pendidikan dalam negara tersebut. Indonesia adalah negara yang perhatian dan berusaha mendorong kemajuan pendidikan dengan memberikan pendidikan kepada setiap masyarakat dengan wajib belajar selam 9 tahun yaitu sampai tingkat sekolah menengah pertama (SMP) dengan kata lain minimum pendidikan setiap warga negara dimana pun berada dalam wilayah Indonesia wajib menempuh pendidikan sampai tingakt SMP, bagi masyarakat yang lanjut usia dan tidak dapat menempuh pendidikan normal atau formal pemerintah memberikan program belajar paket A dan B. Paket A adalah setingkat dengan sekolah dasar (SD) dan paket B 
diberikan untuk tingkat dan selevel dengan (SLTP), program ini dimaksudkan untuk memberikan penyetaraan pendidikan kepada masyarakat yang tidak mendapatkan pendidikan formal di bangku sekolah.

Data dari Organisation for Economic Co-operation and Development (OECD) untuk peringkat pendidikan dunia, negara maju diukur berdasarkan tingkat pendidikannya. (UNESCO) (2017), menyebutkan Indonesia berada pada peringkat ke 10 untuk kualitas guru dari 14 negara berkembang. Dengan demikian bisa dibilang kinerja guru Indonesia dibawa rata rata dan tergolong dibawah standar yang ada, dibandingkan dengan negara lainnya di Asia Tenggara, data dari UNESCO menjelaskan kualitas guru sangat rendah, perlu adanya tinjauan dan penelitian untuk melihat kinerja guru agar kualitas dan kompetensi guru terangkat dan mampu bersaing dengan bangsa lain didunia. Data sekolah menengah atas yang ada di Batam menurut dinas pendidikan KEPRI pada bulan februari 2018 adalah untuk sekolah menengah kejuruan (SMK) berjumlah 86 sekolah, terdapat sekolah berstatus negeri sebanyak 7 sekolah negeri dan 25 sekolah swasta, sedangkan untuk sekolah menengah atas (SMA) ada sebanyak 55 sekolah dengan rincian untuk sekolah negeri sebanyak 22 dan sisanya sebanyak 33 sekolah swasta (Dinas Pendidikan Provinsi Kepri, 2018). Guru merupakan gerbang utama dalam membentuk karakter siswa dalam mempersiapkan siswa dan siswinya dalam menhadapi dunia kerja dan melanjutkan ke perguruan tinggi nantinya. Penelitian ini menjadi referensi bagi manajemen dan pihak sekolah guna memberikan peningkatan kinerja guru disekolah tersebut bagi dinas Pendidikan Kepri menjadi masukan untuk perbaikan kapasitas guru sekolah negeri maupun sekolah swasta melalui faktor kecerdasan emosional sorang tenaga pengajar, sebagai dasar dan pertimbangan untuk memberikan pelatihan kepada guru sekolah dalam meningkatkan kompetensi dan kualitas guru. Kinerja guru merupakan kemampuan seseorang dalam implementasikan pengetahuan dengan baik dan tepat, melalui aspek intelektual, (Mehmood et al., 2013). Definisi lain menyatakan bahwa kinerja guru merupakan kegiatan dan kegiatan seseorang dalam kelas belajar. Brophy and Good (1992). Kinerja adalah capaian nyata dari seseorang dari rencana yang telah ditetapkan sebagai harapan dari organisasi, definisi lainnya menyebutkan kinerja merupakan prestasi standar yang disusun sebagai acuan sehingga dapat monitor dan diarahkan sesuai dengan posisinya dan tanggung jawab kerja dengan standar yang dibuat. (Dessler, 2009) menyatakan kinerja sesuai dengan standar yang sudah ditentukan untuk dicapai. Simanjuntak (2005) mengemukakan kinerja adalah tingkat pencapaian hasil atas pelaksanaan tugas tertentu.

\section{Penelitian terdahulu Terkait Kinerja Guru}

(Satriyono, 2018), (Mark, 2017), menganalisa kecerdasan emosional terhadap kinerja guru, dimana emotional intelligence terdiri dari bebrapa faktor seperti kesadaran diri, keterampilan sosial, pengaturan diri, dan lain sebagainya, dari penelitian tersebut menunujukan kecerdasan emosional berpengaruh positif terhadap kinerja seseorang. Saran dari penelitian adalah melakukan inovasi terkait dengan metode pembelajaran dalam kelas, meningkatkan kompetensi 
akademik dan non akademik, setiap guru diharapkan mengembangkan kecerdasan sosial dilingkungan sekolah dan bisa menghadapi masalah. (Mohammad \& Amirian, 2016), (Mehmood et al., 2013). (Asrar-ul-haq, Anwar, \& Hassan, 2017) penelitian yang dilakukan di Pakistan melihat kinerja guru dari kecerdasan emosional yang terdiri dari rasa percaya diri, pencapaian, pengembangan, konflik manajemen dan kesadaran emosional, dari data yang diperoleh menjelaskan ada pengaruh positif serta signifikan terkait kecerdasan emosional dengan kinerja guru.

Banyak penelitian melihat dan menganalisa faktor yang menentukan kecesrdasan emosional seorang guru yang berhubungan dan berpengaruh terhadap kinerja, beberapa tahun terakhir sebuah penelitian tentang kecerdasan emosional telah dilakukan di salah satu negara maju, tingkat kecerdasan emosional memilki keterkaitan dan hubungan dengan lamanya mengajar yang dilakukan seseorang serta ditentukan oleh tingkat pendidikan orang tersebut, (Mohammad \& Amirian, 2016), (Kannaiah, 2015), (Gunu \& Oladepo, 2014). Dalam penelitian lain juga dijelaskan bahwa kecerdasan emosional memiliki hubungan dengan kepuasan kerja, disana juga disebutkan bahwa kecerdasan emosional juga memiliki hubungan dengan komitmen organisasi, dan dari kesemuanya variabel tersebut terdapat dampak dan pengaruh yang signifikan dan positif pada masing masing variabel (Anari, 2012), (Hopkins, Neil, Williams, \&
Foundation, 2007), (Naseer, Chishti, Rahman, \& Jumani, 2011). Penelitian lain menempatkan (kesadaran diri, pengaturan diri, motivasi, empati, dan keterampilan sosial) dan kemampuan karyawan memiliki pengaruh terhadap kinerja karyawan (Akbar, 2011), (Okpara et al., 2015), (Pekaar et al., 2017) baik tidaknya kinerja seseorang ditentukan oleh kecerdasan emosional yang mereka memiliki dan merupakan kunci utama dalam memecahkan permasalahan yang ada serta dapat mengurangi konflik diantara sesama karyawan, seseorang dengan kecerdasan emosional yang tinggi dapat mengontrol diri sendiri dengan sehingga selalu muncul pikiran yang jernih dalam menanggapi setiap masalah. (Shamsaei, Yousefi, \& Sadeghi, 2017)

Beberapa peneliti yang ada diIndonesia meneliti tentang pengaruh kecerdasan emosional terhadap kinerja seseorang dalam sebuah organisasi atau insatansi, hasilnya menunjukan kinerja yang baik dan bagus ditentukan oleh tingkat inteligensi seseoarang dengan kata lain kecerdasan emosional memiliki dampak yang nyata terhadap kinerja karyawan dimana mereka bekerja. (Hendriani \& Garnasih, 2013) menggabungkan kecerdasan emosional dengan beban kerja dan tingkat stres dalam kerja mengukur baik buruknya kinerja seseorang karaywan dalam melakukan tugasnya, masing masing variabel dalam penelitiannya juga sejalan dengan penelitian sebelumnya kesemua variabel memiliki hubungan dan pengaruh terhadap capaian kerja dan prestasi kerja orang tersebut. 
(Prabu \& Puspitasari, 2015), (Karini, 2014). Ternyata kecerdasan emosional tidak saja mempengaruhi kinerja karyawan atau guru, dalam penelitian lainnya juga dilakukan penelitian terhadap mahasiswa dimana capain mahasiswa juga ditentukan oleh tingkat kecerdasan emosional mahasiswa tersebut. Dimana hasil penelitian pada mahasiswa accounting universitas 11 Maret ditentukan oleh seberapa mampu mahasiswa mengolah kecerdasan emosional mereka sehingga dapat memotivasi diri mereka dalam menyelesaikan belajar dengan baik. (Santoso, 2018).

\section{METODE PENELITIAN}

Ini termasuk jenis penelitian kuantitatif dimana dalam penelitan ini menggunakan data primer untuk melihat pengaruh antara satu variabel dengan variabel lainnya, cara pengambilan data melalui kuesioner dan wawancara terhadap responden guna mengetahui sejauh mana tanggapan responden terhadap variabel dalam penelitian ini, (Sugiyono, 2015). Dalam penelitian ini yang menjadi populasi adalah guru atau tenaga pengajar pada Sekolah Menengah Atas (SMA) yang ada di Batam, data dari Dikmen provinsi Kepri terdapat 22 sekolah negeri yang ada dikota Batam dengan jumlah guru sebanyak 440 orang guru dengan status ASN atau PNS. Yang menjadi responden atau sampel dalam penelitian ini adalah bahagian dari populasi dimana jumlah sampel yang dijadikan responden adalah sebanyak 217 orang Sampel, (Krejcie dan Morgan, jumlah populasi 500 dengan confidance $=95 \%$ jumlah sampel 217 responden)

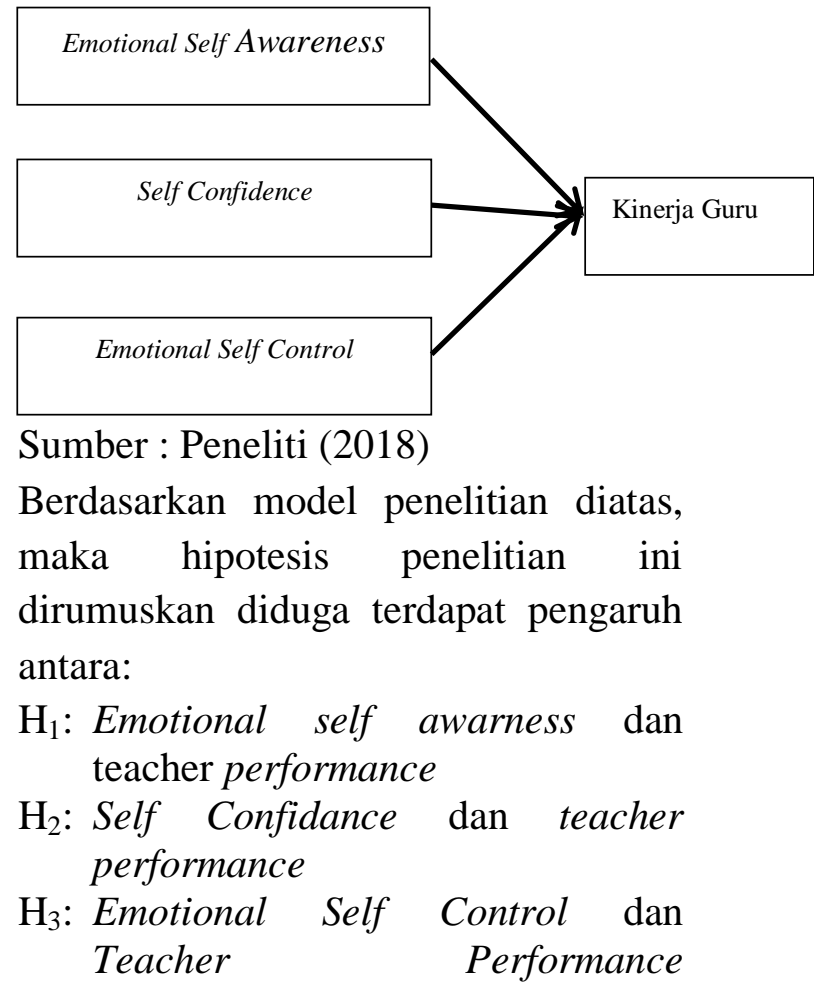

\subsection{Operasional Variabel}

Tabel. 3.1

\section{Operasional Variabel}

\begin{tabular}{|c|c|c|}
\hline Variabel & Definisi & Sumber \\
\hline $\begin{array}{ll}\text { Emotional } & \text { Self } \\
\text { Awareness (X1) } & \end{array}$ & $\begin{array}{l}\text { Cara mengenali persaan } \\
\text { seseorang }\end{array}$ & $\begin{array}{l}\text { Asrar-ul-haq, Anwar, } \\
\text { \& Hassan, (2017), }\end{array}$ \\
\hline Self Confidance (X2) & $\begin{array}{l}\text { Berhubungan dengan } \\
\text { kjujuran dan integritas }\end{array}$ & $\begin{array}{l}\text { Asrar-ul-haq, Anwar, } \\
\text { \& Hassan, (2017), }\end{array}$ \\
\hline $\begin{array}{c}\text { Emotional Self } \\
\text { Cotrol (X3) }\end{array}$ & mengatur emosi & $\begin{array}{l}\text { Mehmood et al., } \\
\text { (2013). }\end{array}$ \\
\hline
\end{tabular}

Sumber: Mehmood et al., (2013), Asrar-ul-haq, Anwar, \& Hassan, (2017)

\section{Teknik Pengumpulan Data}

Pengumpulan data dilakukan dengan menbagikan kuesioner kepada responden. Alasan dipilihnya kuesioner sebagai pengambilan data karena cenderung lebih bersifat lansung sebagai opini, sikap, dan pengalaman dari responden.

\section{Metode Analisis Data}

Data yang dikumpulkan akan diproses dengan menggunakan program SPSS (Statistical Package for the Social Science) untuk 
menggambarkan pengaruh variabel independen terhadap variabel dependen. Beberapa pengujian yang

\section{HASIL DAN PEMBAHASAN}

Pengumpulan data dilakukan dengan menyebarkan kuesioner sebanyak 230 sesuai dengan data minimum yang akan dijadikan sample dalam penelitian ini yaitu sebanyak 217 responden, untuk mengantisipasi kuesioner tidak kembali, rusak dan lainnya maka

\section{Tabel 1}

Tabel Distribusi Kuesioner

\begin{tabular}{cc}
\hline Keterangan & Jumlah \\
\hline Kuesioner yang disebarkan & 230 Eksemplar \\
Kuesioner yang tidak kembali & 5 Eksemplar \\
Kuesioner tidak lengkap & 5 Eksemplar \\
Kuesioner yang outlier (-3 Z Score & 0 Eksemplar \\
3) & \\
Kuesioner yang digunakan & 220 Eksemplar \\
\hline
\end{tabular}

Sumber : Data Primer Diolah (2018)

Karakteristik umum responden berdasarkan kategori yang telah diuraikan dapat dilihat pada Tabel 2 Pada penelitian ini dapat disimpulkan bahwa karakteristik jenis kelamin responden menunjukkan laki - laki lebih banyak dari pada perempuan dengan rata - rata usia berada pada 20 - 29 dan bekerja sebagai pegawai swasta dengan tingkat pendidikan terakhir yaitu strata 1 . dilakukan untuk penelitian ini antara lain statistik deskriptif, dan uji hipotesis.

kuesioner yang dibagikan sebanyak 230 eksemplar kepada responden. Penyebaran kuesioner dilakukan dalam waktu 3 bulan. Kuesioner tersebut dibagikan kepada guru Sekolah Menengah Atas (SMA) negeri di Kota Batam.

Tabel 2

Karakteristik Umum Responden

\begin{tabular}{lrrr}
\hline Demografi Responden & Frekuensi & $\begin{array}{c}\text { Persent } \\
\text { ase }\end{array}$ \\
\hline Jenis Kelamin & & 50 \\
Laki - laki & 110 & 50 \\
Perempuan & 110 & \\
& Antara usia 20 - 30 & & 33,6 \\
& Antara usia 31 - 40 & 74 & 43,6 \\
Antara usia 41 - 50 & 96 & 22,3 \\
Diatas usia 50 & 49 & $\mathbf{0 , 5}$ \\
Status Perkawinan & 1 & 26,8 \\
Belum Menikah & & 73,2 \\
Menikah & 59 & 1,8 \\
Pendidikan Terakhir & 161 & 83,6 \\
$\quad$ Diploma & & 10,9 \\
\hline Strata 1 & 4 &
\end{tabular}

Sumber: Data Primer Diolah (2018)

Tabel 3

Karakteristik Variabel

\begin{tabular}{lccccc}
\hline Variabel & N & Min & Max & $\begin{array}{l}\text { Rata- } \\
\text { Rata }\end{array}$ & $\begin{array}{c}\text { Standar } \\
\text { Deviasi }\end{array}$ \\
\hline Kesadaran Emotional diri 220 & 3,0 & 15,0 & 11,3 & 2,2 \\
Rasa Percaya Diri & 220 & 7,0 & 25,0 & 18,5 & 3,5 \\
Kontrol Emosi Diri & 220 & 5,0 & 20,0 & 15,4 & 2,6 \\
Kinerja Guru & 220 & 13,0 & 40,0 & 32,0 & 4,2
\end{tabular}

Sumber : Data Primer Diolah (2018)

\section{Hasil Uji Outlier}

Data-data responden yang merupakan data outlier atau data yang menyimpang dari rata-rata tersebut akan dikeluarkan dari analisis data 
selanjutnya. Uji outlier ini menggunakan z-score (standard score) dengan batasan -3 sampai dengan +3 . Jika data memiliki nilai z-score lebih kecil dari -3 atau lebih besar dari 3 . Hasil uji outlier tidak terdapat dalam kuesioner

\section{Hasil Uji Kualitas Data}

Berdasarkan hasil uji validitas untuk semua variabel, item yang tidak valid adalah sebanyak 12 pertanyaan sehingga jumlah keseluruhan pertanyaan yang digunakan dalam penelitian ini adalah sebanyak 31 pertanyaan:

Reliabilitas adalah sebuah cara untuk mengetahui apakah setiap butir item pada variabel itu dijawab secara konsisten.

\section{Tabel 4}

Hasil Uji Reliabilitas

\begin{tabular}{lcc}
\hline \multicolumn{1}{c}{ Variabel } & $\begin{array}{c}\text { Cronbach's } \\
\text { Alpha }\end{array}$ & Kesimpulan \\
\hline $\begin{array}{l}\text { Emotional Self } \\
\text { Awareness }\end{array}$ & 0,759 & Reliabel \\
Rasa percaya diri & 0,703 & Reliabel \\
Kontrol emosi diri & 0,776 & Reliabel \\
Teachers & 0,774 & Reliabel \\
Performance & & \\
\hline
\end{tabular}

Sumber : Data Primer Diolah (2018)

\section{Hasil Uji Hipotesis}

Hasil uji $\mathrm{F}$ test menunjukkan perolehan nilai $\mathrm{F}$ sebesar 71,6 dengan tingkat signifikansi sebesar 0,000 ( $\mathrm{p}<$ 0,05). Hal ini menunjukkan bahwa emotional self awareness, rasa percaya diri, kontrol emosi diri secara bersama memberikan pengaruh yang signifikan terhadap kinerja guru, atau dengan kata lain model regresi dapat digunakan untuk memprediksi kinerja guru. Hasil uji $\mathrm{F}$ dapat dilihat pada Tabel 5 dibawah ini.
Tabel 5

Hasil Uji F

\begin{tabular}{lccl}
\hline \multicolumn{1}{c}{ Model } & F & Sig. & Kesimpulan \\
\hline $\begin{array}{l}\text { 1. Regression Residual } \\
\text { Total }\end{array}$ & 71,678 & 0,000 & Signifikan \\
\hline
\end{tabular}

Sumber : Data Primer Diolah (2018)

Uji $\mathrm{t}$ dilakukan untuk melihat tingkat signifikansi dari masing masing variabel independent terhadap variabel dependent. Hasil uji dapat dilihat dari nilai signifikansi yang ada pada tabel 6

Tabel 6

Hasil Uji t

\begin{tabular}{|c|c|c|c|c|}
\hline \multirow{2}{*}{ Model } & \multicolumn{2}{|c|}{ Uji t } & \multirow{2}{*}{$\begin{array}{l}\text { Signifikan } \\
\text { si }\end{array}$} & \multirow{2}{*}{ Kesimpulan } \\
\hline & B & $\mathbf{T}$ & & \\
\hline (Constant) & 4,028 & 3.285 & 0,001 & \\
\hline $\begin{array}{l}\text { Kesadaran emosional } \\
\text { diri }\end{array}$ & 0,003 & 0,022 & 0,033 & Signifikan \\
\hline Rasa percaya diri & 0,025 & 0,303 & 0,762 & $\begin{array}{c}\text { Tidak } \\
\text { Signifikan }\end{array}$ \\
\hline Kontrol emosi diri & 0,116 & 1,211 & 0,027 & Signifikan \\
\hline
\end{tabular}

Sumber : Data Primer Diolah (2018)

\section{Hipotesis 1}

Hasil pengujian pada Tabel 6 menunjukkan pengaruh kesadaran emosional diri terhadap kinerja guru. Penelitian ini didukung oleh penelitian sebelumnya Mohammad \& Amirian, (2016), Naqvi et al., (2016), Nwadinigwe, I.P and Azuka-Obieke, (2012), Mehmood et al., (2013). Ahmed et al., (2016), Yahaya et al., (2012), Kalpana \& Shoba, (2016), Asrar-ul-haq, Anwar, \& Hassan, (2017), Arabsarhangi, (2014). (Anari, 2012), (Hendriani \& Garnasih, 2013). Akhtar \& Ghufran, (2017), (Wong et al., 2012), (Shamsaei et al., 2017), (Gharetepeh, Ameneh Yahya, Safari Pashaei, Tahereh Razaei, 2015). (Cherian \& Jacob, 2013) (Adeyemo, 2007), (Lam \& Kirby, 2013), (Naseer 
et al., 2011), (Kim \& Lee, 2015), (Jordan \& Troth, 2009), (Ramesh et al., 2016), (Carmeli \& Josman, 2009), (Pekaar et al., 2017), (Chew et al., 2013), (Caruso et al., 2010), (Carmeli \& Josman, 2009), (Ayiro, 2009), (Santoso, 2018).

\section{Hipotesis 2}

Hasil pengujian pada Tabel 6 menunjukkan pengaruh rasa percaya diri terhadap kinerja guru. rasa percaya diri memiliki nilai koefisien sebesar 0.025 pada tingkat signifikansi sebesar $0,762$. ( $p>0,05)$. Artinya ada pengaruh positif dan tidak signifikan antara rasa percaya diri dan kinerja guru hasi menunjukan sama dengan hipot Penelitian ini didukung oleh penel 0,818
sebelumnya Mohammad \& Amirrall, (2016), Naqvi et al., (2016), Nwadinigwe, I.P and Azuka-Obieke, (2012), Mehmood et al., (2013). Ahmed et al., (2016), Yahaya et al., (2012), Kalpana \& Shoba, (2016), Asrar-ul-haq, Anwar, \& Hassan, (2017), Arabsarhangi, (2014). (Anari, 2012), (Jordan \& Troth, 2009), (Ramesh et al., 2016), (Carmeli \& Josman, 2009), (Pekaar et al., 2017), (Chew et al., 2013), (Caruso et al., 2010), (Carmeli \& Josman, 2009), (Ayiro, 2009), (Santoso, 2018).

\section{Hipotesis 3}

Hasil pengujian pada Tabel 6 menunjukkan pengaruh kontrol emosi diri terhadap kinerja guru. kontrol emosi diri memiliki nilai koefisien sebesar 0.116 pada tingkat signifikansi sebesar 0,027. ( $\mathrm{p}<0,05)$. Artinya terdapat pengaruh positif dan signifikan antara kontrol emosi diri dan kinerja guru hasil ini sesuai dengan hipotesis. Penelitian ini didukung oleh penelitian sebelumnya Mohammad \& Amirian, (2016), Naqvi et al., (2016), Nwadinigwe, I.P and Azuka-Obieke,
(2012), Mehmood et al., (2013). Ahmed et al., (2016), (Gharetepeh, Ameneh Yahya, Safari Pashaei, Tahereh Razaei, 2015). (Cherian \& Jacob, 2013) (Adeyemo, 2007), (Lam \& Kirby, 2013), (Naseer et al., 2011), (Kim \& Lee, 2015), (Jordan \& Troth, 2009), (Ramesh et al., 2016), (Carmeli \& Josman, 2009), (Pekaar et al., 2017), (Chew et al., 2013), (Caruso et al., 2010), (Carmeli \& Josman, 2009), (Ayiro, 2009), (Santoso, 2018).

\section{Tabel 7}

Hasil Uji Koefisien Determinasi (Adjusted $\mathrm{R}^{2}$ )

R Square Adjusted R Square Std. Error of the Estimate

0,669

0,650

2,46404

Sumber : Data Primer Diolah (2018)

Hasil analisa $R$ Square Adjusted menunjukkan bahwa variabel yang diteliti dalam penelitian ini menunjukkan pengaruh sebesar $65 \%$ terhadap variabel Kinerja dari Guru SMA di Kota Batam, sehingga dalam penelitian ini terlihat sangat jelas pengaruhnya dan sisanya yaitu ada pada variabel yang tidak diteliti dalam penelitian ini, sehingga hal tersebut dapat menjadi keterbatasan dan juga rekomendasi untuk penelitian ke depannya.

\section{KESIMPULAN, REKOMENDASI DAN IMPLIKASI MANAJERIAL}

Berdasarkan pembahasan yang telah diuraikan, maka dapat ditarik kesimpulan bahwa terdapat pengaruh antara kesadaran emosional diri dan kinerja guru. Hasil pengujian juga membuktikan bahwa terdapat pengaruh positif tetapi tidak signifikan antara rasa percaya diri dan kinerja guru. Hasil penelitian selanjutnya membuktikan bahwa terdapat pengaruh 
antara kontrol emosi diri dan kinerja guru hasil ini sesuai dengan hipotesis.

\section{Rekomendasi}

Berdasarkan hasil penelitian ini maka untuk penelitian masa depan, bisa dilakukan kembali penelitian yang sama dengan objek penelitian yang berbeda dengan melibatkan guru guru pada sekolah menengah atas swasta yang ada dikota batam atau daerah lainnya guna melihat secara komprehensif pengaruh kecerdasan emosional guru terhadap kinerja guru. Penelitian lain juga dapat dilakukan pada bidang yang berbeda seperti industri dengan menambahkan variabel lainnya seperti kepemimpinan, dan budaya organisasi dengan ukuran sampel yang lebih besar dan waktu penelitian yang lebih lama Asrar-ulhaq, Anwar, dan Hassan, (2017). Pengembangan instrument dapat disesuaikan dengan objek atau sektor yang dipilih dalam penelitian berikutnya guna mendapatkan hasil yang lebih maksimal. Penelitian ini hanya mengandalkan data primer disarankan untuk penelitian masa depan menggabungkan data ini dengan data sekunder yang lebih handal dalam bentuk penelitian kualitatif dan kuantitatif.

\section{Implikasi Manajerial}

Hasil penelitian menunjukan bahwa kecerdasan emosional untuk setiap variabel berpengaruh terhadap kinerja guru, satu variabel "rasa percaya diri' memilki pengaruh positif tetapi tidak signifikan ini mengindikasikan bahwa variabel rasa percaya diri tidak berkontribusi besar dalam mempengaruhi kinerja guru. Sedangkan untuk variabel lainnya berpengaruh positif dan signifikan terhadap kinerja guru, jawaban responden cendrung positivisme untuk setiap variabel, dan bisa ditinjau juga dari kuesioner yang disebarkan hasil penelitian juga menunjukan hasil nilai positif dilihat dari rata rata jawaban responden. dengan demikian langkah yang dapat dilakukan oleh kepala sekolah adalah dengan melakukan komunikasi melalui pendekatan human approach dengan melakukan beberapa program pelatihan dan kegiatan yang diakomodir seperti pelatihan, seminar, ceramah khusus bermaterikan kecerdasan emosional yang dapat membangkitkan kecerdasan emosional guru, pengajian agama yang dilakukan secara rutin untuk memberikan pencerahan terhadap hati dan perasaan setiap guru, menyelenggarakan kegiatan outbond atau family gathering sehingga akan terjalin ikatan emosional dan keakraban diantara seluruh guru yang akan berdampak pada kepuasan kerja dan peningkatan kinerja guru di sekolah menengah atas (SMA) Kota Batam.

\section{DAFTAR PUSTAKA}

Adeyemo, D. A. (2007). Moderating Influence of Emotional Intelligence on the Link Between Academic Self-efficacy and Achievement of University Students. Psychology and Developing Societies 19, 2(2007), 199-213.

https://doi.org/10.1177/097133360 701900204

Ahmed, Z., Sabir, S., Rehman, Z., Khosa, M., \& Khan, A. (2016). The Impact of Emotional Intelligence on Employee ' $\mathrm{s}$ Performance in Public and Private Higher Educational Institutions of Pakistan. IOSR Journal of Business and Management (IOSRJBM), 18(11), 63-71. https://doi.org/10.9790/487X1811056371 
Akbar, A. (2011). A comparative Study of the Relation between Emotional Intelligence and Employee ' s Performance. Procedia - Social and Behavioral Sciences, 30, 386389.

https://doi.org/10.1016/j.sbspro.20 11.10.076

Anari, N. N. (2012). Teachers : emotional intelligence, job satisfaction , and organizational commitment. Journal of Workplace Learning, 24(4), 256269.

https://doi.org/10.1108/136656212 11223379

Arabsarhangi, M. (2014). The Relationship between Selfawareness and Learners , Performance on Different Reading Comprehension Test Types among Iranian EFL Elementary Learners. Academy Publisher Manufacturing in Finland, 4(4), 675-685. https://doi.org/10.4304/tpls.4.4.675 $-685$

Asrar-ul-haq, M., Anwar, S., \& Hassan, M. (2017). Impact of emotional intelligence on teacher' s performance in higher education institutions of Pakistan. Future Business Journal, 3(2), 87-97. https://doi.org/10.1016/j.fbj.2017.0 5.003

Ayiro, L. P. (2009). An Analysis of Emotional Intelligence and the Performance of Principals in Selected Schools in. Advances in Developing Human Resources, 11(6), 719-746. https://doi.org/10.1177/152342230 9360958

Carmeli, A., \& Josman, Z. E. (2009). The Relationship Among Emotional Intelligence , Task Performance , and Organizational Citizenship Behaviors. Human Performance, 19(4), 37-41. https://doi.org/10.1207/s15327043 hup1904

Caruso, D. R., Mayer, J. D., \& Salovey, P. (2010). Journal of Personality Relation of an Ability Measure of Emotional Intelligence to Personality. Journal of Personality Assessment, 2(February 2015), 306-320. https://doi.org/10.1207/S15327752 JPA7902

Cherian, J., \& Jacob, J. (2013). Impact of Self Efficacy on Motivation and Performance of Employees. International Journal of Business and Management, 8(14), 80-88. https://doi.org/10.5539/ijbm.v8n14 p80

Chew, B. H., Zain, A., \& Hassan, F. (2013). Emotional intelligence and academic performance in first and final year medical students: a cross-sectional study. Medical Education, 13(44), 30-40.

Gharetepeh, Ameneh Yahya, Safari Pashaei, Tahereh Razaei, M. (2015). Emotional intelligence as a predictor of self-efficacy among students with different levels of academic achievement at Kermanshah University of Medical Sciences. Journal of Advances in Medical Education \& Professionalism Original, 3(2).

Gunu, U., \& Oladepo, R. . (2014). Impact of Emotional Intelligence on Employees 'Performance and Organizational Commitment: A Case Study of Dangote Flour Mills Workers. University of Mauritius Research Journal, 20, 1-32.

Hendriani, S., \& Garnasih, R. L. (2013). Pengaruh kecerdasan intelektual dan kecerdasa emosional terhadap kinerja guru SMAN 8 Pekanbaru. Journal Economic, 21, 1-10.

Hopkins, M. M., Neil, D. A. O., 
Williams, H. W., \& Foundation, T. C. (2007). Emotional intelligence and board governance : leadership lessons from the public sector. Journal of Managerial Psychology, Vol. 22 No(April 2015), 683-700. https://doi.org/10.1108/026839407 10820109

Indrianto, N., \& Supomo, B. (2012). Metodologi penelitian bisnis untuk akuntansi dan manajemen (Pertama). Yogyakarta: BPFEYogyakarta.

Jordan, P. J., \& Troth, A. C. (2009). Managing Emotions During Team Problem Solving: Emotional Intelligence and Conflict Resolution Managing Emotions During Team Problem Solving: Emotional Intelligence and Conflict Resolution. Human Performance, 2(April 2013), 195218.

Kalpana, R. P., \& Shoba, K. (2016). A Study on Emotional Intelligence and Job Performance among the Private School Teachers in Tiruvellore District, Tamilnadu. Int. Journal of Management and Development Studies, 5(4), 119127.

Kannaiah, D. (2015). A Study on emotional intelligence at work place. European Journal of Business and Management, 7(24), 147-155.

Lam, L. T., \& Kirby, S. L. (2013). The Journal of Social Is Emotional Intelligence an Advantage? An Exploration of the Impact of Emotional and General Intelligence on Individual Performance. The Journal of Social Psychology, 10(April 2013), 37-41.

Mark, J. A. (2017). Journal of Accounting \& The Effect of
Emotional Intelligence on Employee' s Job Performance: the Moderating Role of Perceived Organizational Support, 6(3). https://doi.org/10.4172/21689601.1000243

Mehmood, T., Qasim, S., \& Azam, R. (2013). Impact of Emotional Intelligence on the Performance of University Teachers. International Journal of Humanities and Social Science, 3(18), 300-307.

Mohammad, S., \& Amirian, R. (2016). Emotional Intelligence and Selfefficacy of Iranian Teachers: A Research Study on University Degree and Teaching Experience. Journal of Language Teaching and Research, 7(3), 548-558.

Naqvi, I. H., Iqbal, M., \& Akhtar, S. N. (2016). The Relationship between Emotional Intelligence and Performance of Secondary School Teachers. Bulletin of Education and Research, 38(1), 209-224.

Naseer, Z., Chishti, S., Rahman, F., \& Jumani, N. B. (2011). Impact of Emotional Intelligence on Team Performance in Higher Education Institutes. International Online Journal of Educational Sciences, 3(1), 30-46.

Nwadinigwe, I.P and Azuka-Obieke, U. (2012). The Impact of Emotional Intelligence on Academic Achievement of Senior Secondary School Students in Lagos , Nigeria. Journal of Emerging Trends in Educational Research and Policy Studies (JETERAPS), 3(4), 395-401.

Okpara, A., Open, N., Island, V., Lecturer, A., Kingdom, U., \& State, O. (2015). Self awareness and organizational performance in the nigerian banking sector. European Journal of Research and Reflection in Management 
Sciences, 3(1), 53-70.

Pekaar, K. A., Linden, D. Van Der, Bakker, A. B., Born, M. P., Pekaar, K. A., Linden, D. Van Der, ... Born, M. P. (2017). Emotional intelligence and job performance: The role of enactment and focus on others, emotions. Human Performance, 30(2-3), 135-153. https://doi.org/10.1080/08959285. 2017.1332630

Prabu, A. A. A., \& Puspitasari, M. (2015). Kecerdasan emosi, stress kerja, dan kinerja Guru SMA. Jurnal Kependidikan, 45(2), 142 155.

Ramesh, Thavaraj, S., \& Ramkumar. (2016). Impact of emotional intelligence on academic achievement of college students -. International Journal of Business Management \& Research (IJBMR), 6(2), 25-30.

Santoso, A. L. (2018). Emotional Intelligence and Job Performance of Accounting Students Undertaking Internships. Journal of Management and Marketing Review, 3(1), 40-47.

Satriyono, G. (2018). Pengaruh kecerdasan emosional terhadap kinerja guru. Jurnal Ekonomi Universitas Kadiri, 3(1), 31-46.

Shamsaei, F., Yousefi, F., \& Sadeghi, A. (2017). Relationship Between Emotional Intelligence and SelfEsteem in Bachelor Students of Nursing and Midwifery Schools in Hamadan. Avicenna J Neuro Psyh Physio, 4(1), 1-6. https://doi.org/10.5812/ajnpp.4448 5.Research

Sugiyono. (2015). Metodologi Penelitian Bisnis. ALFABETA Bandung.

Wong, M. C. S., Lau, T. C. M., \& Lee, A. (2012). The Impact of Leadership Programme on Self-
Esteem and Self-Efficacy in School : A Randomized Controlled Trial. Open Access, 7(12). https://doi.org/10.1371/journal.pon e.0052023

Yahaya, A., Sar, N., Juriah, E., Junaidah, D., Yahaya, N., \& Boon, Y. (2012). The Impact of Emotional Intelligence Element on Academic Achievement. Archives Des Sciences, 65(4), 2-17. 